\title{
İskenderiye Okulu ve İslam Düşüncesi Üzerindeki Etkileri*
}

\section{Alexandria School and Its Effects On Islamic Thought}

\author{
Nesim Aytepe ${ }^{\text {a,*** }}$ \\ ${ }^{a}$ Doktora Öğrencisi, Ankara Sosyal Bilimler Üniversitesi, Felsefe ve Din Bilimleri, Dinler Tarihi, Ankara/Türkiye. \\ ORCID: 0000-0001-9373-6495
}

\section{MAKALE BİLGİSI \\ Makale Geçmişi: \\ Başvuru tarihi: 30 Mart 2021 \\ Düzeltme tarihi: 05 Temmuz 2021 \\ Kabul tarihi: 15 Temmuz 2021}

\section{Anahtar Kelimeler:}

İskenderiye Okulu,

İslam Düşüncesi,

Alegori,

Hiristiyanlık

\section{ARTICLE INFO}

\section{Article history:}

Received: 30 March 2021

Received in revised form 05 July 2021

Accepted 15 July 2021

\section{Keywords:}

Alexandria

School,

Islamic Thought,

Allegory,

Christianity

\section{ÖZ}

İslami ilimlerin klasik dönemde farklı kültürlerden etkilendiğine dair iddialar söz konusudur. Bu iddialarda temel amaç, İslami ilimlerin gelişim döneminde orijinallikten yoksun olduğunu kanıtlamaktır. Buna karşı İslam düşüncesini savunanlar gelişim döneminde her ne kadar etkileşimler olsa bile İslami ilimlerin kendi iç dinamikleri üzerinden gelişimini sürdürdüğünü iddia etmektedirler. Bu tartışmayı somut veriler üzerinden neticeye bağlamak üzere İskenderiye Okuluna bakılabilir. İskenderiye Okulu, tarihsel olarak İslami ilimlerin teşekkül döneminden önce varlığını büyük oranda kaybetmiştir. Bununla birlikte, İskenderiye Okulunda temsil edilen düșünce ve kültürel birikim, farklı şekillerde etkisini sürdürmüştür. Bu çalışma, bir taraftan İslami ilimlerin farklı kültürel çevreden ne oranda etkilenmiş olabileceğini İskenderiye Okulu örneğinden hareketle ortaya koymayı hedeflerken, diğer taraftan İskenderiye Okulunun bu etkiyi nasıl oluşturduğunu analiz etmeyi amaçlamaktadır.

\section{Giriş}

İslam düşüncesinin teşekkül döneminde, Müslümanların yabancı kültür tecrübesine sahip olmadıklarını ve ortaya koydukları ürünlerin İslam'ın dinamiklerinden beslendiğini söylemek mümkündür. İlk ortaya çıkan Tefsir, Hadis ve Fıkıh gibi ilimlerin iç dinamiklerinden kaynaklandığı konusunda bir ihtilaf yoktur. Buna rağmen Müslümanların

\begin{abstract}
A B S T R AC T
There are claims that Islamic sciences were influenced by different cultures in the classical period. The main purpose of these claims is to prove that Islamic sciences lack originality in the development period. On the other hand, those who defend the idea of Islam claim that even though there are interactions during the development period, Islamic sciences continue to develop through their own internal dynamics. In order to conclude this discussion with concrete data, one can refer to the Alexandria School. Historically, the Alexandria School has largely lost its existence before the formation period of Islamic sciences. However, the thought and cultural accumulation represented in the Alexandria School continued to influence in different ways.
\end{abstract}

* Bu çalıșma, 7 Aralık 2020 tarihinde Muş Alparslan Üniversitesi İslami İlimler Fakültesinde düzenlenen İslam Düsüncesinde Eleștiri Kültürü ve Tahammül Ahlâkı II (Klasik Dönem- M. VII.- XII. Yüzyıllar) Sempozyumunda sunulan bildirinin geliştirilmiş halidir.

** Sorumlu yazar/Corresponding author.

e-posta: naytepe@gmail.com 
Oryantalistlerin bu iddiasına karşı çıkanlar, Batının yükselişinde Müslümanların etkisinin olduğunu, İslam düşüncesinde farklı kültürlerle karşılaşma ve etkileşimler olsa da bu etkileşimin oryantalistlerin iddia ettiği kadar büyük olmadığını ileri sürmüşlerdir. Onlara göre Müslümanlar Yunanlılara ait bilgileri sadece aktarmamış aynı zamanda içselleştirip zenginleştirmişlerdir (Weidner, 1973: 114). Bazılarına göre Batı, bugün kendi yükselişini Doğu'ya, daha özelde Müslümanlara borçludur. Dolayısıyla bu düşünceyi savunanlar, modern Batı uygarlığının yükselmesinde Müslümanların önemli katkısı olduğunu ileri sürmüşlerdir ( Hobson, 2015: 43).

Müslümanların Yunan düşünce birikimini sadece aktaran bir köprü olarak görülmesi ispat gerektiren bir iddiadır. İslam düşüncesinin klasik döneminde çeviri ve şerh dişında orijinal eserlerin telif edilmesi bile İslam düşüncesinin salt köprü vazifesi gördüğü şeklindeki değerlendirmeleri yanlış çıkarmak için yeterlidir (Ülken, 1983: 1). Müslümanlar, antik kültüre ait birçok hatayı da düzeltmiş, kendilerine özgü sonuçlara ulaşmışlardır. Nitekim Cebir ve Kimya ilimlerinin Müslümanların eliyle müstakil bir ilim haline geldiği rahatlıkla söylenebilir (Weidner, 1973: 115).

Kültür ve medeniyetler arasındaki etkileşimin doğal olduğunu söyleyen O'Leary'e göre medeniyet ya da kültür bir millete/gruba atfedilemez (O’Leary 1949: 4 ). Kendi başına bağımsız bir kültür ya da medeniyet yoktur. Kültür ve medeniyetler, diğer medeniyetlerle etkileşim içindedirler. $\mathrm{Bu}$ anlamda İslam düşüncesinin oluşumunda da farklı medeniyetlerin katkısının olması doğaldır (Bozkurt, 2016 130).

İslam düşüncesinin klasik dönemde başka kültürlerden ne oranda etkilendiğini anlamak için İskenderiye okuluna bakılabilir. İskenderiye Okulu, farklı inançları bir arada tutması yönüyle merkezi bir konuma sahiptir. İlk kurulduğunda Helenistik felsefi öğretiyi savunan İskenderiye Okulunun (Didaskaleion) bașta Yahudi ve Hıristiyan teolojisi olmak üzere pek çok din ve inanç ile irtibatlı olduğu düşünülmektedir. İskenderiye okulunun bu çeşitliliği şehrin coğrafi, kültürel ve tarihi dokusundan kaynaklanmaktadır. Aslında sadece bir okul değil birden fazla okulun olduğu söylenebilir. Bu okulların tümünde felsefe ve alegorizm hâkim bir görünüm arz etmektedir. Platon ve Aristoteles gibi büyük felsefecilerin; Septizm, Stoacılık ve Yeni Eflatunculuk gibi önemli felsefi akımların merkezi olan İskenderiye Okulları, aynı zamanda matematik, astronomi, tıp, sosyoloji, mantık, coğrafya gibi bilimlerin de gelişmesine öncülük etmiştir (O’Leary 1994: 8).

İskenderiye Okulu, kadim bir felsefî gelenek ile semavi bir din arasındaki etkileşimin boyutlarını göstermesi açısından da önemlidir. $\mathrm{Bu}$ anlamda miladi üçüncü ve dördüncü yüzyıllarda hem Patristik felsefeyi ${ }^{1}$ hem de konsilleri etkileyerek en büyük dönüşümü Hıristiyanlık ile kurduğu ilişkiyle yaşamış olan İskenderiye Okulunun, NesturiMonofizit Kiliseleri ve Hiristiyan Kilise Babaları aracılığıyla Müslümanları etkilediği iddia edilmiştir. (Ülken, 1983: 9). Ayrıca Matematik, Geometri, Cebir, Tıp, Astronomi gibi ilimlerin sistemleşerek gelişmesine öncülük

${ }^{1}$ Patristik felsefe ya da patroloji, MS I.-IV. yüzyıllar arasını kapsayan dönemi ifade etmektedir. eden İskenderiye Okulunun, bu alanlarda Müslümanlara önemli bir miras bıraktığı ifade edilmiştir (Ülken, 1983: 15).

İskenderiye Okulunun (okullarının) İslami ilimleri hangi boyutta etkilediğini anlamak için tarihsel sürecini ve öne çıkan özelliklerini açıklanması gerekmektedir.

\section{2. İskenderiye Okulu}

Asya, Afrika ve Avrupa'yı birbirine bağlayan yolların birleştiği noktada bir liman kenti olan İskenderiye, adını ve mimari planını Büyük İskender'den almıştır (Forster, 1922: 26). Kurucusu kadar efsanevi olan bu şehrin cazibesi Büyük İskender'den sonra daha çok kendisini göstermiştir (Getty, 1996: 10). Büyük İskender'in ölümünden sonra Batlamyus (Ptolemaios) hanedanı zamanında şehrin önemi daha da artarak, doğu ve batı ülkelerinden gelenlerin bilim ve ticaret merkezi olmuştur (Droysen, 2007: 288; Andre Bonnard, 2004: 212). İskenderiye, sadece Helenistik dönemde değil kısmen Roma döneminde de Yakın Doğu'nun entelektüel ve bilimsel yaşamında öncü bir rol oynamıştır (Getty, 1996: 26).

Antik çağın yazarları tarafindan yazıtlarda veya papirüslerde sık sık övgü dolu sözler alan İskenderiye'nin nüfus dağılımı, şehir planına uygun olarak Yunan alfabesinin ilk beş harfiyle belirlenmiştir. ${ }^{2}$ Şehir bir dünya vatandaşı tanımına uygun olarak, antik dönemde neredeyse insanlığın tüm 1rklarının yaşadığı mekân vasfinı taşımaktadır (Getty, 1996: 40). Nitekim Hıristiyanlığın, ortaya çıktıktan sonra zamanla İskenderiye'de Yeni Eflatuncu renge bürünmesinde, şehrin Antik dönemde birçok felsefi akımın uğrak yeri olmasının sağlamış olduğu eklektik yapının etkisi bulunmaktadır ( Utku, İstanbul, 2010: 33-50).

İskenderiye kentinin dinsel, bilimsel ve kültürel çeşitliliği ve mevcut okullara yabancı ögrencilerin kayıt olması bu okullara çoğulcu ve ekümenik bir karakter de vermektedir ( Hugh, 1911: 1).

İskenderiye kenti, felsefe, matematik, teoloji, filoloji gibi bilimin öncülüğünü yapmış gerçek anlamda bir üniversiteydi. Bu yükseköğrenimin dikkat çeken bir özelliği felsefenin gitgide entelektüel elit tabakaya ait olmaktan çıkıp bireylerin çoğunu ilgilendiren bir konu haline gelmeye başlamasıydı (Roy Macleod, 2020: 180).

Antik dönemde, inşa edilen tapınaklarda dönemin en önemli araştırma merkezinin olduğu İskenderiye, içinde yaklaşık 700 bin cilt kapasiteli büyük bir kütüphane ile etrafında birçok okul barındırmıştır. Tarihin ilk bilinen araştırma enstitüleri anlamına gelen bu okullar Doğu topraklarında Helen kültürünün yayıcısı konumunda olmuşlardır (Carmen Chica, 2016: 134).

Hıristiyanlığın ortaya çıkmasından önce antik dönem İskenderiye'sinde mevcut olan okulların her birisi birer tapınak görevini üstlenmiştir. Bu dini tapınaklar, Museion,

\footnotetext{
2 Şehir, Yunan alfabesinin ilk beş harfiyle belirlenen beş bölüme ayrılmıştı. Doğuda A mahallesi vardı ve orada B mahallesinin önemli bir kısmında olduğu gibi İskenderiye'nin önemli Yahudi cemaati yaşıyordu.Yerli Mısırlılar batıda, eski Rhakotis köyünün çevresinde yoğunlaşmıştı. Diğer mahallelerde ise şehrin Rum ya da Helenleşmiş nüfusunun çoğunluğu yaşıyordu (Getty, 1996: 40)
} 
Serapium, Sebastian ve Scriptorium(Didaskaleion) aynı zamanda kendi kuruluş amacına ${ }^{3}$ uygun öğretimlere ve kitap koleksiyonlarına sahip olmuştur (Malaty, 1994: 8). Bu kitap koleksiyonları, zamanla çağının en büyük kütüphanesi unvanını getirmiştir. $\mathrm{Bu}$ okulların genelinde, hazırlık sürecinde ortak olan eğitim programının uygulandığ1 belirtilmektedir. Bu programda Fen, Matematik, Yunan ve Roma edebiyatı, Mantık ve Sanat gibi dersler işlenmiştir. Yine bu okulların genelinde alegorizm, felsefe ve gnostizm gibi özellikler ön planda olmuş olup her okulun kendi kuruluş amacına uygun hale getirilerek aktarılmıştır (Malaty, 1994: 9) İnşa edilen tapınakların içinde, bu okullara destek olarak kurulan kütüphane zamanla dev bir komplekse dönüşmüştür. Kütüphanenin yönetimi doğrudan kral tarafindan seçilmiştir (https://www.ancient.eu/article/207/what-happened-to-thegreat-library-at-alexandria/(Erişim tarihi 05.06.2020).

İskenderiye Kütüphanesinde yapılan en önemli çalışma çeviridir. Nitekim Eski Ahit'in İbraniceden Yunancaya Septuagint olarak bilinen ilk tercümesinin yapıldığı yer İskenderiye Kütüphanesidir (Carmen, 2016: 134). Eski Ahid'in bu tercümesi yetmiş iki kişi tarafından yetmiş iki günde yapıldığı için "Yetmiş" anlamında "Septuagint" denmiştir. Tercüme, Helenizmin tesiri altına girmiş ve Yunanca konuşmaya başlayan İskenderiyeli Yahudi cemaati için yapılmıştır (Adam, 2010: 24) İbranice bilmeyen ve Yunanca konuşan Yahudiler bu çeviriden faydalanmışlardır. Yahudi teolojisi ile Yunan felsefesini İskenderiye Okulunda harmanlamaya çalışan Yahudi düşünür Philo, bu çeviriyi eksen almıştır (Hugh, 1911:573575) Nitekim Philo'nun fikirleri daha sonra Hiristiyan Kilise Babaları Clement ve Origenes tarafindan geliştirilecektir (Hussein El-Zohary, 2016: 1-20).

İskenderiye'de özellikle Clement ve Origen'in temsil ettiği Hıristiyan İskenderiye Okulu, metinlerin karşılaştırılması, düzenlenmesi, kopyalanması işlevini yürütürken metin kritiği yöntemini kutsal metinlere uygulamaktadır. Böylece buradaki Hıristiyan bilginler, Hıristiyan inançlarını, Yunan kültürüne entegre etmekle meşgul oluyorlard1. Bu geleneğin İskenderiyeli Philo ile birlikte geldiği görülmektedir. İskenderiye kentinin hem pagan hem de Hıristiyan kültürel dokusu bu geleneğin oluşumunda önemli olmuştur (Malaty, 1994: 31).

Hıristiyanlık tarihinde ve teolojisinde önemli bir yeri olan konsillerin aldığı kararlarda İskenderiye Okulunun etkisi olmuştur. Örneğin ilk konsil 325 yılında İznik'te toplanmış ve bu konsilde İskenderiye ekolunu temsil eden görüş kabul edilmiştir. Konsilde İskenderiye patriği olan Athanasyus, Baba ile Oğul'un aynı özden olduğunu kabul etmeyen ve Oğul'a ikincil bir statü veren Aryus'u heretik (sapkın) kabul etmişti (Doru, 2007: 16). Yine 431 Efes konsilinde İskenderiye Okulu'nu temsil eden İskenderiye Kilisesi, Meryem için Thetokos (Tanrı annesi) ifadesini kullanan bir görüş ileri sürmüştür. İskenderiye Okulunun bu görüşüne karşın, İsa'nın hem insani hem de tanrısal yönü olduğunu söyleyen ve Meryem'e “Christotokos (İsa'nın annesi)

\footnotetext{
3 Bu tapınaklar kimisi pagan, kimisi gnostik sır dinleri, kimisi de Yahudiliği veya Hıristiyanlığı temsil etmektedir. Bunlar içerisinde Akdeniz dünyasında öğrencileri en çok cezbeden ve meşhur olan “Museion”dur. (Malaty, 1994: 8).
}

ifadesini kullanan Nesturiler heretik (sapkın) kabul edilmiştir ( Aydın-Duran, 2019: 53; Doru, 2007, 17).

İskenderiye Okulu ve 3. yüzyılın son yarısında kurulan Suriye'deki Antakya Okulu, Erken dönem Hıristiyanlıkta teoloji ve İncil tefsir çalışmaları için iki büyük merkezdi. İskenderiye Okulu, Kutsal Yazıları yorumlamak üzere insan ve Tanrı arasındaki birliği vurgulayan bir Kristolojiyi tamamlamak için alegorik yöntemi kullanırken, Antakya Okulu ise İsa'nın şahsında insan ile Tanrı arasındaki ayrımı tasvir eden bir Kristolojiyi savunmuştur. Aynı zamanda daha gerçek (literal) (zaman zaman tipolojik) veya tarihsel bir yöntem ileri sürmüştür (https://www.copticchurch.net/ Erişim tarihi 05.06.2020).

Hıristiyanlığın ilk dört yüzyılında etkili olan İskenderiye Okulu, Apostolik ${ }^{4}$ bir merkez olarak hem teolojik hem de liturjik açıdan fikirlerini Akdeniz, Mezopotamya ve Afrika'nın kuzey bölgelerine taşımıştır (Aydın-Duran, 2019: 52). İskenderiye Okulu miladi 3. ve 4 yüzyıllarda "Patristik" adıyla felsefî-teolojik bir külliyat ortaya koymuştur. Külliyatta Yunanca eserler ve bu eserlere uygun Hıristiyanlık şerhleri vardır. "Kilise Babaları" olarak anılan bu yazarlardan Platon'a dayanarak Aristo şerhleri yazanlar olduğu gibi Aristo'ya dayanarak Platon diyaloglarını şerh edenler de bulunmaktadır. Fakat bunların dışında Plotin'e dayanarak haşiyeler (Glose) yazanlar da vard1. $\mathrm{Bu}$ eserlere dair İslam kaynaklarında pek az bilgi bulunmaktadır (Ülken, 1983: 14).

Teolojik olarak Hıristiyanlığı şekillendiren İskenderiye Okulu'nda ön plana çıkan unsur felsefedir. Önceleri daha seküler olan felsefi içerikler zamanla Hıristiyanlığın gelişimiyle, önce ahlak, sonra din felsefesi ve son olarak da Hıristiyan teolojisi (ilahiyat) alanlarına yönelmiştir. Epikurosçuların şüpheciliği ve Stoacıların çileci idealleri dört asırdan fazla entelektüellerin yaşamlarını etkilediğinden, bu okullarda Hiristiyanlar tekrar Platonculuğu benimsemeye başladılar. $\mathrm{Bu}$ durum, Aristoteles'in, Stoacıların ve Yeni-Pisagorcuların fikirlerinin çoğunu özümseyen ve zamanın çeşitli felsefi ve dini hareketlerinin düşünceleri üzerinde etkisi olan yeni bir Platonculuğun başlangıcını işaret ediyordu. Bu eğilim, 2. yüzyılın ikinci yarısında Orta Platonizm adlı felsefi bir hareketle doruğa ulaştı (Oliver, 2015: 94). İskenderiye'de gelişen bu Yeni Eflatunculuğun sonraki yüzyıllarda metafiziğiyle batı dünyasının mistisizmi ve teolojisi üzerinde büyük etkileri olduğu görülmektedir (Macleod, 2006: 180).

İskenderiye Okulu felsefi anlamda, Platonculuk ile Hıristiyan öğretisini birleştirmeyi amaçlayan Yeni Platoncu çizgide yer alan bir okul olarak bilinir. Huristiyanlığ felsefe açısından yorumlayan İskenderiye Okulu'nun düşünce üretiminde Yeni Platoncu öğreti başat konumda olmuş olsa da seçmeci ve gizemli eğilimler de sergilemiştir (Bakkal, 2006: 56). Antik çağ felsefesinin son halkasını oluşturan Plotinus ile başlayan Yeni Eflatunculuk erken dönem Hıristiyanlık düşüncesini etkilerken, aynı zamanda Hıristiyanlığın kendisi de İamblichos, Proclos gibi geç dönem Yeni Eflatuncuları etkilemiştir (Arslan, 2010: 10). Din ve felsefe uyumu üzerine bir eğilimi devam ettiren

\footnotetext{
${ }^{4}$ Apostolik, İsanın havarileri tarafindan kurulan ve ona isnat edilen merkez ya da kilise.
} 
İskenderiye Okulunda, Hıristiyan filozofları/kilise babaları tarafindan Yunan Felsefesinin kavramları, dinî inançları aydınlatmada bir araç olarak kullanılmış ve felsefe artık dini bir renk kazanmıștır (İnan, 2006: 2/261; Vural, 2016: 29; Namık:1993: 45).

Miladi 1. yüzyılın ilk çeyreğinde çeşitlilik arz eden okulların zamanla Hıristiyanlığın güçlenmesiyle din felsefesine evirildiği ve sonra da Hıristiyan ilahiyatını şekillendiren bir yapıya büründüğü söylenebilir. Bunun yanında Hıristiyan teolojisi dışında Yeni Eflatunculuğu merkeze alan okulların da olduğu görülmektedir. $\mathrm{Bu}$ okulların varlığı miladi 5.asırdan sonra etkisini yavaş yavaş yitirecektir. Nitekim MS. 415'ten İskenderiye sokaklarında Hıristiyan bir kalabalık tarafindan öldürülen filozof ve matematikçi Hypatia(M.S 360-415) ve MS 430'da İskenderiye'li Hierocles gibi kişilerin olması az da olsa politeist Yeni Eflatuncu okulların varlıklarını devam ettirdiğini gösterirken dönemin Huristiyan teolojisi karşısında çok etkili olmadıklarını göstermektedir (ElZohary, 2016: 1-20).

Özetle modern arkeolojik ve akademik araştırmalar, İskenderiye'de "Geç Antik Dönem" olarak bilinen tıp ve felsefenin ağırlıkta olduğu bir dönemin varlığından bahseder. Buna göre İskenderiye'deki bilim ve felsefe, kesintiye uğramadı. Bu etki MS 1. yüzyılın ilk yarısında İskenderiyeli Philo'nun yazılarında devam etti ve MS 2. yüzyılda gelişti. Plutarch (ö. MS 120), felsefe için İskenderiye'ye gelirken aynı yüzyılın ortalarında Galen tıp ve felsefe için gelir. Milattan sonra üçüncü yüzyılda Ammonius Saccas ve öğrencisi Plotinos (ö. 270), Hıristiyan filozofları İskenderiyeli Clement ( ö. 215) ve öğrencisi Origenes (ö. 254) isimleri bulunmaktadır (El-Zohary, 2016: $1-20$ )

\section{3. İskenderiye Okulu'nun Temel Yöntemi: Alegori}

Mısır'ın kıyı şehri olan İskenderiye'de daha önce bir okul değil birden fazla okulun olduğunu ve bu okulların inşa edilen tapınaklar içinde mevcut kitap koleksiyonları ile desteklendiği ifade edilmişti. Bu okulları diğerlerinden ayıran ve dişardan gelen öğrenciler için cazibe merkezi olmasında öne çıkan özellik, felsefe ve alegorizmin sıklıkla kullanılmasıdır. Felsefenin Yeni Eflatunculuk akımının hangi boyutlarda olduğunu yukarda ifade edildi. Bunun yanında diğer bir özellik de alegoridir. Dolayısıyla alegorik yorum geleneğini tarihsel kökenleriyle bilmek, İskenderiye Okulunun diğer dinlerin teolojisi üzerindeki etkisini anlamak bakımından son derece önemlidir. Alegori yöntemin anlaşılması için alegori kavramını tahlil etmek gerekir.

Alegori kelimesi Grekçe "başka bir şey söylemek" anlamına gelen "alla-egorein" kökünden gelmektedir. "Bir metinde, lafzî anlama paralel veya lafzî anlamdan başka bir anlamın kastedilmesini ifade eden alegori, dinî bağlamda kullanıldığında bir rivayetin veya sanat eserinin, ahlâkî ve teolojik değerlerin sembolü olarak yorumlanması anlamına gelir.” (Tarakçı, 2010: 183-213; Harrington, 2003: 291; Rudolf, 1968: 237).

Daha önce temelleri atılan alegorik yorumlama yönteminin, kutsal metinlere uyarlanma tarzı Yahudi filozof Philo ile başlatılır (Malaty, 1994: 30 Aykıt: 2011: 111-113). Kutsal metinleri tefsir etme anlamında da kullanılan "alegorik tefsir" Yunanca "allegoria”, "resimsel konuşma şekli” gibi anlama sahiptir. Bu, metnin gizli anlamlarını ortaya çıkarma, yorumlama gayreti, remiz ve kinayeli anlatımı ifade eder. $\mathrm{Bu}$ yorum metodunu İskenderiye Yahudileri Eski Ahit tefsirinde, İskenderiye ekolüne bağlı Hıristiyan ilahiyatçıları ise 2. yüzyıldan itibaren Kitabı Mukaddes tefsirinde sıkça kullanmışlardır (Gündüz, 2017:2).

Kutsal Kitap yazılarının batıni yorumlanması geleneği, Brahman ve Budist bilginlere kadar gitmektedir. Bu bilginler, Kutsal kitapları Vedaları yorumlarken metnin zahiri anlamı yerine batini anlamına göre tefsir yapmışlardır. ${ }^{5}$ Fakat kutsal metin ile felsefe arasındaki uçurumu sistematik bir şekilde kapatma çabası Philo ile başlamaktadır (Malaty, 1994: 31) İskenderiye'li Yahudi filozof Philo, Yunan felsefesinin kökenin İbranice kaynaklara kadar izlenebileceğini iddia etti. Ayrıca Yahudi Tanrı kavramlarını Yunan felsefi terminolojisine çevirdi. Philo'nun Tanrı'ya dair alegorik yorumlama tarzı, ortaçă̆ Yahudi ve Hıristiyan filozoflarını etkiledi (https://www.historicjesus.com/glossary/jewsofalexandria.h tml Erişim tarihi 05.06.2020).

Philo'nun alegorik yorumlama yöntemi, önce Pavlus'un öğretilerini etkiledi ve bu etkinin İncillerde (özellikle Yuhanna incilinde) izleri görüldü. Daha sonra Hıristiyan Kilise Babalarından olan Clement ve Origen ile birlikte sıkı bir şekilde İskenderiye Hıristiyan okulunda kullanılmaya başlanmıştı (Oliver, 2015: 70).

Alegorizm ile kutsal metinler yorumlanırken bazı ilkelere dikkat edilmektedir. Buna göre alegorik yorumu kullanırken, metnin kendisi Tanrı'nın itibarı ve karakteri ile çelişmedikçe, tercümanın metnin özü olan ilk anlamına uyması gerekir. Bu, literal anlamda kullanılan bir anlamdır. Fakat metinlerde özellikle tercümelerde Tanrı için olumsuz ya da Tanrı aleyhine bir mana çıkıyorsa o zaman alegorik yorumlamaya başvurulur (Duncan, 2011: 17).

İskenderiyeli St. Clement, alegorik yorumu kullanan ve sonradan kullanılmasını sağlayan ilk Hıristiyan ilahiyatçısı (yazar) olarak kabul edilir." Yine Clement, "Yunan felsefesiyle Hıristiyan öğretisi arasında bir düşmanlık olmaması gerektiğini ileri sürmüştür. Clement, hem Yunan felsefesini Hıristiyanlar için kabul edilebilir kılmak hem de Yunan felsefe ve düşünce geleneğinden gelen entelektüellere Hıristiyanlığın düşündükleri gibi bir cahiller dini olmadığını göstermek istemiştir.” (Arslan, 2010: 308; Malaty, 1994: 30).

Hıristiyan teolojisinin önemli mimarlarından ve İskenderiye okulunun öncülerinden biri olan Origen, kutsal metinleri yorumlama geleneğini sistematik hale getirmiştir (Ramelli, 2012: 1-17). Origen sonrasinda kutsal metinler, felsefe ve Platonizm 1şı̆ğında yorumlanmıştır (Ramelli, 2012:1-17).

Origen'in öncelikli amacı, Kitab-1 Mukaddes'te, ifadelerin lafzî olarak anlaşıldığında, özellikle Tanrı'ya nispet edilmesi mümkün olmayan bazı düşünceleri barındıran metinleri farklı bir şekilde yorumlayarak Kitab-1 Mukaddes'in saçma görüşler içeren bir kitap ve

\footnotetext{
${ }^{5}$ Eflatun felsefesinden önce Doğuda bu yorumlama tekniği kullanılmış anlamına gelmektedir. (Şelebi, 2004: 99-108)
} 
Hıristiyanlığın da akıl dışı bir din olmadığını göstermekti (Tarakç1, 2010: 183-213).

Philo ile başlayıp Hıristiyan filozoflar Clement ve Origen'le devam eden kutsal metinlerle ilgili yorumlar, İskenderiye Huristiyan ekolunu temsil etmektedir (Malaty,1994 30; Aykıt, 2011), 111-113). Bu yorumların dini inançları ile Yunan kültürünü uzlaştırmaya çalışması ve kutsal metni anlamlandırmada alegorik yorumu kullanması, İskenderiye Okulunun öne çıkan özelliği olduğu söylenebilir (Blumenthal, 1972: 24).

Philo'nun Tevrat, Origenes'in de Yeni Ahit metnin tefsiri ${ }^{6}$ için yaptığı batini açıklamalar, alegorik yorumlamanın sonucudur (https://www.dunyadinleri.com/tr Erişim tarihi 05.06.2020). Bunu daha ileri götürüp her harfin mecazi bir anlamının olduğunu söyleyen Oklinous gibi İskenderiye Okulu düşünürleri bile olmuştur (Gördük, 2011: 9-47).

İskenderiye Okulu, Hıristiyanlığın Kutsal Kitap yorumları konusunda, alegorik yöntemini esas alırken daha sonra İskenderiye Okuluna muhalif olarak Yahudi nüfusunun fazla olduğu Antakya'da ortaya çıkan Antakya Okulu da literal yöntemi ön plana çıkarmıştır. Yahudi geleneğin metin dilinde Antakya okulunun çizgisini izlediği görülmektedir (Grant, 1984: 64).

İslam düşünce geleneğinde İhvanı Safa, Kur'an'ın mecazi olarak yorumlanması yolunu tercih ederek (yaratma, Adem, şeytan, bilgi ağacı, cennet, cehennem gibi) kimi dini temaların alegorik olarak incelenmesi gerektiğini söylemişlerdir. Kendilerine nispet edilen İsmailiyye akımı tevil anlayışına göre zahir-batın ayrımıyla okumalar yapmıştır (Çetinkaya, 2002, 523-535). Yeni Eflâtunculuk akımının Müslümanlar arasında tanınmasında İhvân-1 Safâ özel bir yere sahiptir. Ansiklopedik risâleleriyle İslâm düşünce tarihinde tam bir eklektisizm örneği veren İhvân-1 Safâ'nın düşünceleri, bulunduğu dönemde hızla yayılmış ve uzun süre etkisini sürdürmüştür. İhvân-1 Safâ risâleleri aynı zamanda Bâtınîler ve İsmâilîler için önemli bir kaynak olmuştur (Uysal, 2000: 22/1-6).

İslam düşünce geleneğinde İskenderiye Okulu'nun ileri sürdüğü alegorik yorumlama yöntemi her disiplin tarafindan farklı şekillerde karşılık bulmuştur. Fıkıh Usulü, Hadis, Tefsir, Kelam gibi alanlarda, daha çok metnin literal anlamını esas alan ve Antakya Okulu'nun gelişmiş kuramı olan çizgi takip edilmiştir. Buna karşın Şii-Batini ve Sufiİşari tefsirlerde metnin batıni yönlerini esas alan bir yorum yöntemi benimsense de İslam düşünce geleneğinin sınırları içinde yer bulamamıştır. Batıdaki hermenutik tartışmalar, İslami ilimlerin içine çekilmeye çalışılsa da Müslümanlar İslami ilimlerde kendi disiplinleri oluşturmuş ve bunu müstakil bir şekilde sunmuşlardır (Paçacı, 2005: 572-589).

\section{Müslümanlarla Hıristiyanlar Arasında Etkileşim Bağlamında İskenderiye Okulu}

Hıristiyanlık, Arap Yarımadasının farklı bölgelerine, değişik zamanlarda ve çeşitli yollarla girmiştir. Hıristiyanlığın Arap Yarımadası'nda etkili oluşu, kuzeyden

\footnotetext{
${ }^{6}$ Hıristiyan tefsir geleneği, III. yüzyıldan itibaren İskenderiye, Kapadokya ve Antalya Okulları etrafında gelişmiştir. (https://www.dunyadinleri.com/tr-TR/dunya-

dinleri/Huristiyankutsalmetinleri/oku_kitab-i-mukaddes-tefsirleri)
}

Roma İmparatorluğu, kuzeydoğudan Sâsânî İmparatorluğu, güneybatıdan bugün Etiyopya olarak bilinen Habeşistan'da olmak üzere üç merkezde gerçekleşmiştir (Sönmez, 2012: 63). Siyasi açıdan Doğu Roma (Bizans) ile Sasani (Pers) İmparatorluğunun aralarındaki savaşların etkisiyle her iki devlet de gücünü kaybetmişti (Sönmez, 2012: 53; Baldick, 1990: 7-8).

Dini açıdan Hıristiyanlar Arap yarım adasının her bölgesine dağılmıştı. Bu bölgede kalan Hıristiyanların çoğunluğunu, Doğu Roma (Bizans) İmparatorluğu'nun resmi inancina aykırı ve bu inancın heretik (sapkın) olarak kabul ettiği özellikle Nesturiler ve Monofizitler oluşturmaktaydı. Doğu Roma İmparatorluğunun Hıristiyanlığın farklı yorumlarına müsamaha göstermemesi ve resmi kilise eliyle aforoz yetkisini kullanmasının etkisiyle bu Hiristiyan grupları, devlet otoritesinin en az hissedildiği sınır bölgelerde yaşama imkânı bulmaktaydı (Sönmez, 2012: 60; Watt, 2000: 7-16).

Bilindiği gibi 431 yılındaki Efes konsilinde Antakya Okulu mensubu Nesturiler, görüşleri heretik (sapkın) kabul edilince Bizans'ın baskısından dolayı Urfa, Nusaybin, Suriye, Mezopotamya ve Arabistan bölgelerine dağılmışlardır (Aydın-Duran, 2019: 53; Doru, 2007: 17). Yine 451 yılındaki Kadıköy konsilinde İskenderiye Okulu mensubu Monofizit (Yakubiler) Hıristiyanlar, görüşleri heretik kabul edilince sonraki yıllarda baskılara maruz kalmışlardır. Sonrasında Mısır üzerinden Habeşistan'a ve güney Arabistan'a gitmişlerdir (Aydın-Duran, 2019: 53). $\mathrm{Bu}$ bölgelerdeki gruplar, teolojik olarak birbirinden farklı olsalar da münzevi keşişler, gezici din adamları ve tüccarlar eliyle Hıristiyanlığı yayma çabası içine girmişlerdir. Bunun sonucunda Arap yarımadasında Hire ve Gassaniler gibi Hıristiyanlığ1 kabul eden Arap kabileleri de olmuştur (Aydın-Duran, 2019: 62,Sönmez, 2012: 261-263).

İslam öncesi dönemlerde Arap Yarımadası'ndaki putperest Araplar siyasî, ticarî ve sosyal gerekçelerle Hıristiyanlarla iletişim içinde olmuştur. Mekkeli Arapların ticarî ilişkiler gereği Hıristiyanlarla karşılaşmaları doğal olarak kültürel etkileşimi İslâm'ın ortaya çıktığı dönem ve sonrasında da devam etmiştir (Sönmez, 2012, 122).

Müslümanların Hıristiyanlarla karşılaşması Habeşistan'daki diyalogla başlamıştır. Hz Peygamber, Mekke müşrikleri tarafından yapılan bask1 ve zulüm üzerine bir grup Müslümanın Habeşistan'a gitmesine izin vermiştir. Kureyşliler, Ashame en-Necâşî’ye bir heyet gönderip Müslümanların iadesini istedilerse de Necâşî müşriklerin teklifini reddetmiştir (Önkal, 1998: 17/459).

Hz. Peygamber, Arap Yarımadası ve çevresindeki Hıristiyanlarla farklı düzeyde ve genelde olumlu münasebetlerde bulunmuştur. Onun, Hıristiyanlarla olan bu ilişkilerinde, Kur'an'ın Hıristiyanlara yönelik bakış açısı belirleyici olmuştur. $\mathrm{Bu}$ bağlamda Kur'an, kimi Hıristiyanları, bazen diğer din mensuplarına oranla $\mathrm{Hz}$. Muhammed'e ve onun getirdiği vahye olumlu bakan, inananlara sevgi bakımından daha yakın, şefkat ve merhamet sahibi kimseler olarak nitelendirmiştir (Maide 5/82). Bazen de çoğu Hıristiyanları, özellikle Hz. İsa ve annesi Meryem'le ilgili konularda aşırıya gitmelerinden (Tevbe 9/31) dolayı şiddetle eleştirmiştir (Sönmez, 2012: 207). Bununla birlikte vahiy süresince Müslümanlarla Hıristiyanlar arasında teolojik ayrılıklar açıkça 
görülüyordu. Özellikle Kur'an'da mübâhele denilen ayetle ${ }^{7}$ ifade edilen, Medine döneminde Necran Hıristiyanlarından bir heyetin Hz. Peygamber'le yaptığı tartışmayla bir başka boyuta gelindi.

Müslümanlar, Hıristiyan grupların en fazla olduğu Şam, Irak ve Misır gibi yerleri fethedince teolojik tartışmalar artarak devam etti. Müslümanlar bu tartışmalarda Hıristiyanlara herhangi bir bask1 yapmıyor ve onların inançlarını muhafaza etmelerine engel olmuyorlardı. Yapılan fetihler, Müslüman olmayanları zorla Müslüman yapmayı amaç edinmiyor, onları yalnızca İslâm devletinin himaye ettiğgi insanlar statüsüne sokmakla yetiniyordu (Fayda, 2006: 12/467). Ayrıca Müslümanların Hıristiyanlarla bu tartışmaları ve ortaya koydukları entelektüel faaliyetler İslam düşüncesinin gelişmesine katkı sağlıyordu.

Müslümanların fethettiği bölgelerde haraç (cizye) denilen belli bir mal karşılı̆̆ında, Hıristiyanların inançlarını korumalarına izin veriliyordu. Bununla birlikte kent nüfusunun büyük bir bölümü, özellikle memurlar ve entelektüeller İslam’ı kabul ediyorlardı (Eliade, 2003: 95).

İslam'ın Doğu Hıristiyanları arasında hızla yayılmass $1,{ }^{8}$ Hıristiyan dünyasının İslam'ı teolojik bir meydan okuma ve rakip olarak görmelerine neden olmuştur. ${ }^{9}$ Doğu Hıristiyanlarının bu bakış açısı sonraki yüzyıllarda Katolikler tarafindan da devam ettirilmiştir (Kalın, 2007: $45)$.

İslam, Hıristiyan din adamları için sadece kötü bir etki değil aynı zamanda tehdit unsuru olarak ele alınmıştır (Hobson, 2015: 118). İslam, Hiristiyanlar tarafindan, ilk başta kendi içlerinden çıkan sapık bir mezhep olarak bilinse de zamanla hızla yayılması İslam düşmanlığında birleşmelerine neden olmuştur (Yücel, 2003: 20).

Nitekim Müslümanların Hıristiyanlarla hoşgörü çerçevesinde yaptıkları teolojik tartışmalar, Haçlı seferleriyle bambaşka bir boyuta evirilmiştir. Dinler tarihçisi Mircea Eliade'nin ifadesiyle Haçlı seferlerinde görülen insanlı dışı tutumlar, Müslümanları tüm Hıristiyanlara düşman etti ve altı yüzyıllık Müslüman egemenliği içinde ayakta kalmayı başaran birçok kilise bu sırada yıkıldı. Haçlı seferlerinden önce İslam'ın hoşgörü tecrübesini gören kiliseler, haçlı seferlerini düzenleyenlere sağladıkları psikolojik ve lojistik destekle yıkılışlarını hazırladılar (Eliade, 2003 115). Hıristiyanlık Avrupa'da Haçlı Seferleri'nde İslamiyet'e karşı Batı uygarlığının siperi haline gelmiştir (Hobson, 2015: 118).

\footnotetext{
${ }^{7}$ Al-i İmran 3/61.

${ }^{8}$ Hiristiyanlara nazaran ilk dönem Müslümanların Yunanca öğrenimine yabancı olarak baktıkları ve hemen almadıkları görülmektedir. İlk kaynaklar selefin tutumundan dolayı farklı öğretilerin İslam beldelerinde pek rağbet görmediğini göstermektedir. (Fazıl, 2001:184).

${ }^{9}$ Bazı oryantalistler, Hıristiyanların ancak yaklaşık 400 yıl sonra bir devlet gücü haline gelinceye kadar yavaş yayılmasını Hıristiyanlara Yunan seküler öğrenimine alışma firsatı vermesinin yanında kendi teolojisinin bozulmasını da neden olduğunu söylemektedir. Buna karşın İslam'ın hızla yayılıp bir güç haline gelmesi sürecinde Müslümanların, Yabancı unsurlara mesafeli olduğunu ve bundan dolayı İslam'ın teolojisinin bozulmadığını ifade ederler. (Grant,2008:503-526).
}

\section{5. İskenderiye Okulu ile İslam Düşüncesi Arasındaki Etkileșim Alanları}

Bilindiği üzere İslam ortaya çıktıktan sonra hızla yayılmıştır. Birçok yer fethedilmiştir. İlk fetihler $\mathrm{Hz}$. Peygamber'in hayatında başlamış ve sonrasında Arap yarımadası kontrol altına alınmıştır. Hz Ömer zamanında, Suriye(636) ve Antakya(637) fethedilmiş ve aynı yıl Sasani İmparatorluğu yıkılmıştır. Mısır 642 'de fethedildi. Eliadenin ifadesiyle "VII. yüzyıl sona ermeden İslam, Kuzey Afrika'ya, Suriye ve Filistin'e, Küçük Asya'ya, Mezopotamya ve Irak'a egemendi. Yalnızca Bizans direniyordu, onun da toprakları çok küçülmüştü." (Eliade, 2003: 95).

Müslümanların fethettiği bu yerlerde en fazla bulunan inanç gruplarının başında Hıristiyanlar gelmektedir. Bu yerlerden birisi olan İskenderiye ile Müslümanların ilk etkileşimi, 641 yılında Hz. Ömer zamanında, Amr bin Âs'ın komutasında buranın fethedilmesiyle başlamaktadır. $\mathrm{Bu}$ fetih, İskenderiye Okulunun Müslümanlarla ile irtibatının başlangıcını oluşturmuştur. $\mathrm{Bu}$ irtibat, aynı zamanda İskenderiye Kütüphanesinin Amr b. As tarafindan yakıldığ 1 iddiasını da beraberinde getirmiştir. Yapılan çalışmalar, bu iddianın doğru olmadığını ve kütüphanenin daha önce MS 391'de yakılmış olduğunu göstermektedir (Butler, 1978: 401; Sandra Toenies Keating, 2008: 43).

Müslümanların fethettiği yerlerin önemli ilim merkezleri olduğu bilinmektedir. $\mathrm{Bu}$ ilim merkezleri, genelde İskenderiye, Antakya, Urfa, Nusaybin, Harran ve Cündişâpur olarak belirtilir. Bunlar aynı zamanda Helenistik kültür merkezleri olarak da bilinmektedir (O'leary, 19-95; Bayraktar, 1988, 37-4 1).

Bu merkezler içerisinde Felsefe Tıp ve Kimya bilimlerinin öncülüğ̈nü yapan İskenderiye, İslam fetihlerinin ilk yıllarında ilmi düzeyini yükseltmek isteyen kişilerin başvurduğu bir merkez durumundaydı (Libera, 2005 30); Tortuk, 2006: 409-425). Zira Müslümanlar antik Yunan kültür mirasıyla tanışmadan önce Atina odaklı Yunan düşüncesinin, Helenistiğin önemli merkezi olan İskenderiye'ye geçtiği görülmektedir (O'Leary, 1949: 4).

Nihat Keklik'e göre, İskenderiye Okulu, ilk fetih aşamasında eski önemini kaybetse de felsefi olarak canlı konumdaydı. $\mathrm{Bu}$ okul akli ilimlerin İslam dünyasına nakledilmesinde büyük rol oynamıştır. Dolayısıyla ilk ilmi araştırmalar sadedinde Müslüman âlimler, antik çağın ilimlerini İskenderiye okulunun temsilcileriyle temasa geçerek almışlardır (Keklik, 1969: 39; Kayacık, 2009: 409418).

Hıristiyanlı̆̆ın ortaya çıkmasından önce İskenderiye'de birçok okul bulunduğu daha önce ifade edilmişti. Aynı şekilde Müslümanlar Mısır'ı fethettiğinde bir değil birden fazla okul görmüşlerdir. İskenderiye Hıristiyan Okulu yanında Helenistik hatta gnostik eğilimlere sahip okullar da bulunmaktadır. Bunun dışında Yahudilerin de kendilerine ait bir okulu olduğu söylenmektedir (Oliver, 2015: 30).

İskenderiye'de Yeni Eflatuncu felsefeye sahip iki okul bulunmaktadır. Bunlardan birisi Yeni Eflatuncu felsefeyi Hıristiyanlıkla ifade etmeye çalışan ve Yahya en-Nahvi'nin temsil ettiği İskenderiye Hıristiyan (Katedral) okulu, diğeri de Proklus'un temsil ettiği ve paganist olarak tanınan Yeni 
Eflatuncu felsefe okuludur. Proklus'un temsil ettiği paganist okul, kapatılan Atina Okulunun devamıdır. Bunun dışında Proklus'un temsil ettiği Yeni Platoncu düşüncede yer alan sudûr düşüncesinin İslam düşüncesinde Farabi ve İbn Sina tarafından geliştirildiği görülmektedir (Doru, 2007: 36; Bakkal, 2006: 56). Yeni Eflatuncu düşüncelere kaynaklık eden İskenderiye Okulunun İslam dünyası ile doğrudan bağlantısının izlerini ilk olarak Ebu Zekeriya Yahya b. Adi' (öl.564/975)de görmekteyiz. İskenderiye Okulu'nun İslam dünyasına tesiri, genel anlamda dolaylı olmuştur (Dawson, 1976: 82-83).

Mısır, Müslümanlar tarafından fethedildiğinde İskenderiye Hıristiyan okulunun başında Stephanus adında bir filozofun olduğu bilgisi İskenderiye Hıristiyan Okulunun varlığının 641 yılına kadar devam ettirdiğini göstermektedir. Ayrıca 529 yılında Atina Okulu kapatıldıktan sonra ${ }^{10}$ filozofların bir kısmı İskenderiye'ye bir kısmı Suriye'ye geçmiştir (Arslan, 2010: 231). Bu bağlamda Ömer b. Abdülaziz'in (717-720) Tıp alanında İskenderiye Okuluna mensup bir hekimin eserini Süryaniceden Arapçaya tercüme etmesi bu dönemde bile İskenderiye Okulunun bilindiğini göstermektedir (Bozkurt, 2016: 130) Bunun dişında bu okullarda Hıristiyanlaşmış Yunan felsefesine ait eserler önce Yunanca yazılıyordu. Fakat sonraları Süryânîceye, Arapça'ya çevriliyordu. Elimizde bulunan ve İslam düşüncesine tesir edenler de daha çok bu eserlerdir (Ülken, 1983: 14).

Müslümanlar Suriye'nin fethiyle de Hiristiyanlığın yetkili temsilcileri ile karşılaştılar. $\mathrm{Bu}$ karşıllaşmada Müslümanların Hıristiyanların inançlarını bildiklerini gösteren iki kaynak bulunmaktadır. Biri 754 yılından önce Yahya ed-Dımeşki tarafından kaleme alınan bir Müslüman ile bir Hıristiyan arasındaki hayali tartışma, ikincisi ise Doğu Süryani Kilisesinin Patriği Mar Timothy ile Halife Mehdi (744-785). arasında 781 yılında gerçekleşen bir tartışmadır. $\mathrm{Bu}$ tartışmanın içeriği, Müslümanların Hıristiyan grupların farklılıklardan ve teolojik tartışmalardan haberdar olduğunu göstermektedir (Wolfson, 2001: 238).

Müslümanların fethettiği yerlerde en fazla bulunan inanç gruplarının Hıristiyanlar olduğu görülmektedir. Arabistan dışına yayılan Müslümanlar, fethettikleri yerlerde Hıristiyan kültürüne ait eserleri yok etmediler. Aksine bu kültürlere karşı büyük bir ilgi ve merak duymuşlardır. Bu merakla birlikte yoğun çeviri çalışmaları başlamıştır (Adamson, 2015: 4. Kayacık, 2004: 9) Bu çalışmalarda, merkezi Hıristiyanlık tarafından heretik sayılan bu Hıristiyanların eserleri Arapçaya çevrilmiştir. Özellikle Süryanicenin Arapçaya yakın olması bu çeviriyi kolaylaştırmıştır. $\mathrm{Bu}$ çeviriler ile Yunan ve İskenderiye okulunun fikirlerinin, İslam düşüncesine girdiği söylenebilir (Ülken, 1983:5).

\footnotetext{
${ }^{10}$ Arslan'ın ifadesiyle "Kapatılan Atina Okulu ile İskenderiye Okulu arasında bariz farklar da bulunmaktaydı. Zira Atina okulunun metafizik tema ağırlıklı eğitimine karşın İskenderiye Okulu edebi ve bilimsel tema ağırlıklı eğitim programı takip etmiştir. Bundan ötürü Atina okuluna mensup Yeni-Platoncu filozoflar İskenderiye Okulu içinde yer alan insanları filozof olmaktan çok bilim adamları olmakla suçlarken, İskenderiye okulu mensupları da Atina Yeni-Platoncularını Yunan felsefesinin geleneksel akılcılığını devam ettirmemeleri, Sır dinlerine önem vermelerinden dolayı küçümsemișlerdir." (Arslan, 2010: 243).
}

Bununla beraber Yunan düşüncesinin Müslüman Araplara birden fazla yoldan ulaşması mümkündür. Özellikle Hint bilim insanları tarafindan geliştirilmiş matematik ve astronomi çalışmalarının aktarıldığını görmekteyiz. Fakat bu çalışma materyallerinin bile Hindistan'a İskenderiye üzerinden deniz yolu ile geçtiği söylenebilir (O'Leaıy, 1949: 5).

Yine o dönemlerde bir Hiristiyan bölgesinin ortasına dikilmiş, pagan bir Yunan kolonisi olan Harran şehri gibi az bilinen ve muhtemelen daha küçük ölçekte de olsa katkıda bulunan kaynaklar vard1 (O'Leary, 1949: 5). Harran okulunun da kendine has özellikleri olsa da onun İskenderiye Okulunun Mezopotamya'daki bir versiyonu olduğu ifade edilmiştir. Buna göre İskenderiye Okulunun mensupları Antakya'ya bir süre (130-140 yıl) yerleşmiş ${ }^{11}$ ve daha sonra Harran'a geçmiştir (Blumenthal, 1972: 24; Bakkal, 2006: 58). Dahası Urfa ve Harran sonrasinda özellikle Harranlı bilim adamlarının yer aldığı Bağdat'a intikal etmiştir (Libera, 2005: 30).

Bağdat Okulunun kurulmasıyla Arap ağırlıklı Müslümanlar yerine acem ağırlıklı bir yapı oluşur (Eliade, 2003: 98). Bu yapının ağırlıkta olduğu dönemlerde kurulan, Bağdat Okulunun, İslam düşüncesinin gelişiminde önemli bir rol oynadığı görülmektedir. Bu okulun teşekkülünde yer alan etkenlerin başında İskenderiye Okulu gelmektedir. İskenderiye Okulu kapandıktan sonra bile buradaki eğitim geleneği Bağdat'a ulaşmıştır (Kayacık, 2004: 9).

İslam felsefesi açısından önemli bir kaynak olan Yunan felsefesinin etkisinin, İskenderiye vasitasıyla olduğu görülmektedir. Müslümanların karşılaştığı İskenderiye, Helenistik felsefeyi ya da Hıristiyanlaşmış Yunan felsefesini temsil etmektedir (Ülken, 1983: 13).

Müslümanlar İskenderiye'yi fethettiklerinde İskenderiye'de mevcut olan okulu Süryaniler temsil etmekteydi. Müslümanlar özellikle Yahya en-Nahvinin öğrencisi İskenderiyeli İstefan'ın eserlerinden yararlandılar. Ancak Süryanilerden sonra İskenderiye Okulunun bu altın çağı kapanmış, okul artık teolojik ve skolastik bir görünüme kavuşmuştur. İskenderiye Okulu, sekizinci yüzyılın başlarında Antakya'ya taşınmıştır. Zira bu dönemde kent eski önemini kaybetmiş, düşünce hayatı ve ticaret bakımından başka merkezler ortaya çıkmıştı (Ülken; 1983: 13).

Müslüman düşünürler, geç İskenderiye felsefesinin metinlerini iki yoldan ulaşmıştır. Birincisi, kendilerinden önce gelen bu fillozofların yazılarına doğrudan erişimdi. Onların bazı eserleri, doğrudan Abbasi dönemindeki çeviri hareketi sırasında Yunancadan Arapçaya çevrildi. İkincisi, m.s. altıncı yüzyılda İskenderiye okulunun varlığı sırasında başlayan Yunanca metinlerin Süryanice çevirileriydi. Bu metinler daha sonra Arapçaya çevrildi (Hussein El-Zohary, 2016: 1-20). Bu çeviriler bir dilden diğerine basit bir geçiş değildi. Çevirmenler antik çağın kültürel mirasçılarının eserlerini aynı zamanda kendilerine mal ediyorlardı. Nitekim Ortaçağda Avrupalıların Yunan düşüncesini

\footnotetext{
${ }^{11} \mathrm{Bu}$ taşınma sürecinin nedenleri arasında, Şam'ın Hilafet merkezi olarak gelişmesi, Mısırla İskenderiye'nin önemini kaybetmesi, İskenderiye'deki okulun Mısır'daki Kıptiler tarafından desteklenmemesi ve aynı zamanda burada Yunanca konuşan kişilerin azalması da etkili olmuştur. Yüksel, 2012: 42).
} 
öğrenme kapıları böylece açılmış oluyordu (Franziska Weidner, 1973: 113).

\section{6. İskenderiye Okulu'nun İslami İlimlere Etkisi}

Müslümanlar Mısır'1 fethettiklerinde İskenderiye Okulunun matematik, astronomi, tıp, sosyoloji, mantık, coğrafya gibi bilimlerine mirasçı olurken Helenistik Hıristiyan felsefesine ait Plotin'den bazı parçalar, Jean Philon, Afrodisias'lı İskender ve Themistius'a ait bir kisim eserleri de görmüşlerdir (Ülken,1983: 15).

Plotinus, Proclus ve diğer Yeni-Platonistlerin yazılarının erken bir tarihten itibaren Arapçaya çevrilmeye başlanmasıyla alegorik yorumların Müslüman geleneği etkilediği iddia edilmiştir. Özellikle bu etkinin Yeni Platoncu başlık bağlamında İslam düşüncesine etki ettiği ifade edilmiştir (http://plato.stanford.edu/entries/arabicislamic-mysticism/ Erişim tarihi 05.06.2020).

Yerel geleneklerle harmanlanan, alegori ve alegorik yorum daha sonra Müslüman felsefesinin, teolojisinin merkezi haline geldi. Bu yöntemin Kindi, Farabi, İbn Sina ve İbn Rüşd gibi Müslüman felsefi teologları etkilediği iddia edilmiştir (http://plato.stanford.edu/entries/arabic-islamic$\underline{\text { mysticism/ Erişim tarihi 05.06.2020) }}$

Philon'un felsefe ile dini uzlaştırma girişimi ve bunun için kutsal metni alegorik olarak yorumlama yöntemi daha sonra Farabi ve İbn Rüşd tarafindan devam ettirilecektir. Philon'da evrenin ikili varlığının söz konusu olduğu görülmektedir. Evren önce Tanrı'da bir idealar dünyası, Akıl veya Logos olarak varlığa sahiptir; daha sonra bu düşünceler fiziksel evren olarak gerçekleştiğinde ayrı bir fiziksel-duyusal varlık kazanmıştır. Philon bu görüşüyle Platon'un İdealarını, Yahudi ve Hıristiyanların Tanrı'sının düşüncelerine özdeş kılan ilk filozof olarak karşımıza çıkar. Daha sonra Farabi bu ikili varlığı kabul edecek ve bunlara İnsan zihni’ kavramını eklemiştir (Arslan, 2010: 26).

Philon, her bakımdan aşkın olan yaratıcı Tanrı ile yaratılmış duyusal, maddi varlıklar arasındaki derin uçurumu kapatmak üzere bazı aracı varlıkları kabul etme ihtiyacı duyar. Ona göre bu varlıklar, Yahudilerin 'melekler', Yunanlıların 'daimonlar' diye adlandırdıkları varlıklardır. Farabi ve İbni Sina ise bu aracı varlıklar olarak Tanrı ile duyusal evren arasında yer alan On Akıl'1 kabul etmiştir (Arslan, 2010: 28).

Müslümanlar fethedilen bölgelerde İskenderiye'nin Helenistik öğretileri ile Süryaniler aracılığıyla temasa geçmişlerdir. Bu öğretilerin en önemlisi mantık alanındadır. Bundan dolayı Arapça ilk mantık yazarları Süryani Hıristiyan âlimlerdi ve onların -mantık ve tıp- arasında yakın bir bağlantıyı içeren- mantık çalışmalarındaki gelenekleri de Arapça konuşan çevreye geçmiş ve Arap mantığının gelişimi için temel oluşturmuştur (Reseber, 2013: 24).

Abbasiler devrinde Mantık tercümelerinin başladığı görülmektedir. O dönemde farklı dinlere mensup olan kişiler, Müslümanlarla tartışmalarında Mantık ilmini kullanıyorlardı (El-Behiy, 1992: 181-182). Bunun üzerine Müslümanlar Aristo mantığına karşı ilgi duymuşlar ve onu defalarca tefsir ve şerh etmişlerdir. Nihat Keklik'e göre mantık ilminin İslam dünyasına girişi, İskenderiye Okulu vasıtasıyla olmuştur (Keklik, 1969: 37).

İbn Haldun, Mantık ilminin İslam dünyasındaki gelişim sürecinde Müslümanların sadece bir aktaran olmadığımı aksine yerine göre reddedip yerine göre değiştirip yerine göre de ekleme yaptıklarını ifade etmiştir. (İbn-i Haldun, 1991: 1161). Dolayısıyla Mantık ilmi, Müslümanların elinde müstakil ve özgün halini almıştır (Keklik, 1969: 69). Ayrıca Müslümanlar arasında asırlarca devam eden şerh geleneğinin önce İskenderiye okulunda daha sonra Süryani Hiristiyanlar eliyle Aristoteles tarafindan ortaya konan Mantık ilmi bağlamında incelendiğini görülmektedir (Keklik, 1969: 68).

Eğitim açısından İskenderiye Okulunun Müslüman dünyasına tesir ettiği de iddia edilmiştir (O'leary, 1949: 1617). Max Meyerholf, "Hocanın yanında, dizi başında okuma geleneği şeklindeki halkalanma biçimi'nin orta çağ boyunca uygulanmasının ilk başlangıcının İskenderiye Okulu olduğunu söyler (Meyerhold, 1980: 60) Bu durumda Aristo şerhleri dışında medrese öğretim yönteminin İskenderiye Okulu vasıtasıyla Müslümanlara geçtiği iddia edilmiştir. Yine İslam dünyasında Bağdat Okulu'nda uygulanan Şerh sisteminin de İskenderiye Okulu metodu olduğu iddia edilmiştir (Rescher, 1964: 36) İskenderiye Okulunun kendine özgü bu öğretim metodu olsa da bunun Müslümanların öğretim metodunu etkilediğini söylemek için kanıt yoktur.

Arslan'a göre, Yeni Eflatunculuk tarafından geliştirilmiş olan felsefi-dinsel model sadece geç dönem Yunan ve Ortaçağ Batı Hıristiyan dünyasını değil, aynı dönemde ortaya çıkan Yahudi ve Müslüman düşünürleri de etkilemiştir. Zira Ortaçağ İslam dünyasında Yunan tarzı felsefe geleneğini başlatan ve onun ilk önemli temsilcisi olan Farabi, esas itibariyle Yeni-Platoncu bir filozoftur. Bu geleneğin Farabi sonrası en ünlü temsilcisi olan ve Geç Ortaçağ Hıristiyan düşüncesi üzerindeki etkisi Farabi'ye oranla daha büyük olmuş olan İbni Sina'da bu etki daha güçlü biçimde kendisini gösterir. Ayrıca İslam dünyasında Aristoteles'e ve Aristotelesçiliğe dönüşün bayraktarlığını yapan İbni Rüşd bile bu etkiden kendini kurtaramamıştır." (Arslan, 2010: 5).

Müslümanlar, Platon ile ilgili eserlere doğrudan değil dolaylı olarak Yeni Platoncu yorumlar aracılığıyla ulaştı. Yeni Eflatuncu yorumcular daha çok "geç dönem" İskenderiye Okulu eserleriyle tanındi. $\mathrm{Bu}$ durumda Müslümanların İran, Suriye, Misır fetihleriyle beraber burada mevcut olan okullar, daha çok "Geç Dönem İskenderiye Okulu" olarak anılan dönemi yansıtır. Geç dönem İskenderiye okulunun en temel özelliği Aristo ve Platonun eserlerini şerh etmeleridir. Müslümanlar burada aslında Aristo ve Platon'un eserlerini şerh edenlerle karşılaştılar. Dolayısıyla İslam dünyasında felsefi düşüncenin şekillenmesinde bu şarihlerin önemli bir etkisi olmuştur (Eliade, 2003: 187).

Cabiri’ye göre “İskenderiye Okulu İslam kültürüne Hermetik edebiyatın girişine zemin hazırlamıştır. Ona göre Hermetizmin ana vatanının İskenderiye olduğunu düşünürsek Hermetik edebiyatın Arap İslam kültürüne iki aşamada girdiğini söylenebilir: İlki, İskenderiye ve onun Filistin'deki muhtemel uzantıları vasıtasıyla gerçekleşmiştir. İkinci aşamada ise Harran ekolu temel 
kaynak olmuştur. Hiç kuşkusuz Harran'dan nakledilen birçok şey aslında İskenderiye ekolüne aittir. Çünkü 'Talim Meclisi' Harran'dan önce İskenderiye'de bulunmaktaydı (el-Cabiri, 2001: 187). Cabiri’nin bahsettiği Talim Meclisi, ilk olarak Ömer b. Abdulaziz döneminde Antakya'ya nakledilmiş, Mütevekkil'in hilafeti döneminde ise birlikte istifadeye açılmıştır." (el-Cabiri, 2001: 187).

Cabirî, Harran Okulu'nun İslam düşüncesinde yarattığı etkiyi İsrailiyâtın dini düşünce ve Hadis'te yarattığı etkiye benzetmekte ve bu okulun felsefi düşünce içinde mütalaa edilemeyecek hurafelere kaynaklık ettiğini söylemektedir (el-Câbirî, 2000: 152). Yine Câbirî, Yunan felsefi mirasının, Yeni-Plâtonculuk formunda İslam dünyasına dört akım şeklinde taşındığını; bu akımlardan ikisinin Meşrikî, diğer ikisinin de Mağribî karakterler taşıdığını ifade etmektedir. Meşrikî karakter taşıyan ekollerden birincisi, İran asıllı mütercimlerin ve yazarların oluşturduğu Fârisî karakterli ekol; ikincisi, Harran mütercim ve bilginlerinin oluşturduğu ekoldür. Yeni Eflatunculuğun Mağribî ekolleri ise, biri Cündişapûr okulunda yetișen Nesturi mütercim ve bilginlerin ekolü olup, Atina okulundan kaçıp gelen Yunanlı bilginler bu ekoldendir. İkinci Mağribî ekol ise İskenderiye'den gelen öğretim konseyidir (el-Câbirî, 2000: 152).

Yahya en-Nahvi, düşünceleri ve felsefi çalışmalarıyla hem Süryani filozofları hem de İslam filozoflarını etkilemiştir. Onun eserleri kendisinden sonra gelen Süryani filozoflar tarafindan Süryanice'ye çevrilmiştir. Yahya en-Nahvinin öğrencisi olan İskenderiye'li İstefan'ın eserleri Emeviler döneminde İskenderiye'de Halid b. Yezid b. Muaviye zamanında biliniyordu (Doru, 2007: 43).

Süryaniler İsa'nın doğası ve diğer konularda kendi felsefi düşüncelerini temellendirmek için Mantık ilmine başvurmuşlardır. Süryanilerin bu teolojik tartışma geleneğinin Müslümanlara geçtiği görülmüştür (Doru, 2007: 46). İskenderiye Okulunun felsefe ve din arasını uzlaştırma çabası ve Yeni Eflatuncu öğretiler ve özellikle südur fikri İslam fillozoflarını etkilemiştir. Ayrıca bu etkilenmede İskenderiye merkezinde Süryani çevirmenlerin rolünün büyük olduğunu söyleyebiliriz (Doru, 2007: 48). İskenderiye Okulunun altıncı asrın sonlarına doğru Hıristiyan bilginlerin idaresine geçmesinden önceki son temsilcisi ise Olympiodoros'tur. Bu okul daha sonra gerek Bizans gerekse İslam dünyasında Yeni-Platoncu etkinin korunması ve devamı bakımından önemli bir rol oynayacaktır (Arslan, 2010: 232).

\section{Sonuç}

İslam düşüncesinin gelişim döneminde farklı kültürlerden ne oranda etkilendiğine dair tartışmalar devam etmektedir. $\mathrm{Bu}$ tartışmalarda İslam düşüncesinin başta Yunan felsefesi ve Hıristiyan inancı olmak üzere farklı inanç ve kültürlerin etkisiyle şekillendiğini dile getirenler olsa da buna dair güçlü bir kanıt ileri süremedikleri söylenebilir. $\mathrm{Bu}$ çalışmada İslam düşüncesinin farklı bir kültür çevresiyle ne boyutta etkileşime girmiş olabileceğini anlamak üzere İskenderiye Okulu inceleme konusu yapılmıştır.

Antik Mısır dini, Yunan felsefesi ve Yahudi kültürünün birlikte harmanlandığı bir düşünce merkezi olan İskenderiye okulunun, kuruluş ruhuna uygun olarak eklektik bir sisteme sahip olduğu söylenebilir. Platon ve Aristoteles gibi büyük felsefecilerin; Septizm, Stoacılık ve Yeni Eflatunculuk gibi önemli felsefi akımların öğretiminin yapıldığı İskenderiye Okulu, aynı zamanda matematik, astronomi, tıp, sosyoloji, mantık, coğrafya gibi bilimlerin de gelişmesine öncülük etmiştir.

İlk kurulduğunda Helenistik felsefi öğretiyi savunan İskenderiye Okulunun barındırdığı çoğulcu ve eklektik yapısıyla başta Yahudi ve Hıristiyan teolojisi olmak üzere pek çok din ve inanç ile irtibatlı olduğu düşünülmektedir. İskenderiye Okulunun çoğulcu ve eklektik yapısının aslında İskenderiye kenti ile bağlantılı olduğu görülmektedir. Zira İskenderiye şehri, sahip olduğu kozmopolit yapısıyla neredeyse insanlığın tüm ırkların yaşadığı mekân vasfını da taşımaktadır.

İskenderiye Okulu ile Yahudi teolojisi arasında İskenderiyeli Philo üzerinden bir ilişkinin olduğunu gösteren çalışmalar, benzer etkinin Konsiller, MonofizitDiyafizit tartışmaları ve Kristoloji gibi konular bağlamında Hıristiyan tarihinde ve teolojisinde de söz konusu olduğunu göstermektedir. En büyük dönüşümü Hıristiyanlık ile kurduğu ilişkiyle yaşamış olan İskenderiye Okulunun, Nesturi-Monofizit Kiliseleri ve Hiristiyan Kilise Babaları aracılığıyla İslam düşüncesini de belli alanlarda etkilediği söylenebilir. İskenderiye'deki bütün okullarda yaygın ve ortak olan Yeni Platoncu'luğun ve alegorizmin belli ölçülerde Müslümanları etkilediğini söylemek mümkündür.

Hıristiyanların kendi teolojilerinde felsefi ve mantıksal çıkarımlarda bulunması geleneğinin, Müslümanların inançlarını savunmada faydası olmuştur. İskenderiye Okulunun mantık, felsefe ve tıp gibi ilimlerde İslam düşüncesi üzerinde belirgin bir etkisi olmuştur. Özellikle Aristoteles ve Platon'un geç dönem şarihlerinin İskenderiye'de ortaya koydukları eserler, Müslüman filozofların Yunan felsefesini yorumlamalarında etkisi olmuştur. Bunun dışında talim meclisi, ders halkası ve ilim metoduna dair konularda da göz ard1 edilemeyecek tesirleri olmuştur.

Sonuç olarak kültürler arası etkileşimi ve diyaloğu doğal kabul ettiğimizde İslam düşüncesinin de farklı zamanlarda diğer kültürlerle karşılıklı alışverişlerde bulunduğunu inkar edilemez. Ancak İslam düşüncesi, İskenderiye Okulu örneğinde de görüldüğü üzere, hiçbir kültürel birikimi olduğu gibi almamış, onu değer ve düşünce dünyasına göre yorumlamış ve özgün bir niteliğe kavuşturmuştur. İskenderiye Okulunun Yahudilik ve Hiristiyanlık üzerinde bıraktığı baskın tesirin bir benzerini İslam düşüncesi üzerinde oluşturmaması da bu konudaki tespitimizi doğrular niteliktedir.

\section{Kaynakça}

Adam, Baki. (2010). Yahudi Kaynaklarına göre Tevrat. İstanbul: Pınar Yayınları.

Adamson, Peter. \& Richard c. Taylor. (2015). İslam felsefesine giriş. (Kaya, M. Cüneyt, Çev.) İstanbul: Küre yayınları.

Andre Bonnard. (2004). Antik Yunan Uygarlığı 3, (Kurt, Kerem, Çev.) İstanbul: Evrensel Basım Yayınları. 
Arslan, Ahmet. (2010). İlkçağ Felsefe Tarihi 5. İstanbul: İstanbul Bilgi Üniversitesi Yayınları.

Aykıt, Dursun Ali. (2011). Hıristiyanlığın Öncüsü Olarak İskenderiyeli Philo. İstanbul: Eskiyeni Yayın Evi.

Aydın, Mahmut- Duran, Asım. (2019). Kur'an ve Hiristiyanlar, İstanbul: Kuramer.

Fayda, Mustafa. (2006). "Mübâhele" Türkiye Diyanet Vakfi İslâm Ansiklopedisi Ankara: TDV Yayınları, $31 / 425$.

Alfred J. Butler,, \& D. Litt., F.S.A., (1978). The Arab Conquest of Egypt ,Edited by P.M. Fraser, Oxford; Oxford University Press.

Alain de Libera. (2005). Ortaçağ Felsefesi. (Meral, Ayşe, Çev.) İstanbul: Litera Yayıncıllk.

Arslan, Ahmet. (2010). İlkçağ Felsefe Tarihi 5. İstanbul: İstanbul Bilgi Üniversitesi Yayınları.

Bozkurt, Nahide. (2016). Mutezilenin Altın Çağı. Ankara: Ankara Okulu Yayınları.

Bakkal, Ali. (2006). Harran Okulu. İstanbul: Şanlıurfa İl Kültür ve Turizm Müdürlüğü Yayınları.

Bayraktar, Mehmet. (1988). İslam Felsefesine Giriş. Ankara: Ankara Üniversitesi Yayınlan.

Gökberk, Macit, (1985). Felsefe Tarihi, İstanbul:Remzi Kitabevi.

Chisholm, Hugh. (1911). "Alexandrian School". Encyclopædia Britannica. Cambridge: Cambridge Press.

Carmen Chica. (2016). Alexandria: History and Culture, Barcelona: Institut d'Estudis Catalans, 2016.

Weidner, Franziska. (1973). Diyanet İşleri Başkanlı̆̆ Dergisi, Dini İlmi Edebi Aylık Dergi, cilt: XII, Sayı: 2, Mart-Nisan. Der Beitrag des İslam zur Wetlkultur (İslamiyet'in Dünya Kültürüne Hizmetleri. (Turan Mehmet, Çev.) Ankara: Emel Matbaacılık.

Droysen, (2007). Büyük İskender Tarihi. (Baykal,B.Sttkı, Çev.) İstanbul: Dharma Yayınları.

De Lacy OiLeary D.D, (1949). How Greek Science Passed ta the Arabs, London: Assyrian International News Agency Books Online.

Doru, Nesim. (2007). Doğu'dan Batı'ya Köprü Süryaniler Felsefe ve Çeviri Geleneği, Ankara: Dipnot Yayınları.

Dawson, Christoper. (1976). Batının Oluşumu. (Tayanç Dinç, Çev.) İstanbul: Dergah Yayınları

Eliade, Mircea. (2003). Dinsel İnançlar ve Düşünceler Tarihi III. (Berktay, Ali, Çev.) İstanbul: Kabalcı Yayınevi.

Fr.Tadros Y. Malaty. (1994). The School of Alexandria Book One Before Origen,Jersey City: St. Mark's Coptic Orthodox Church.

İhsanoğlu, Ekmeleddin. (2008). İslamda Kültür ve Bilgi, Ankara: T.C. Kültür ve Turizm Bakanlığı Yayınları, Helenleştirenlerin Yolu: Yunan Felsefesinin İslam Medeniyetine Katkıları, Abdurrahman Badawi, cilt:5, 439.
el-Câbirî Muhammed Âbid..(2001). Muhammed Abid, Arap-İslam Aklının Oluşumu. (Akbaba, İbrahim, Çev.) İstanbul:Kitabevi Yayınları.

-(2000). Felsefi Mirasımız ve Biz. (Aykut, Said, Çev.) İstanbul: Kitabevi Yayınevi.

Franziska Weidner, Der Beitrag des İslam zur Wetlkultur (1973).İslamiyetin Dünya Kültürüne Hizmetleri. (Özdemir, M. Turhan, Çev.) Dini İlmi Edebi Mesleki Aylık Dergisi XII/2 Ankara: Emel Matbaacılık.

Grant, Edward. 2008 (2020). The Fate of Ancient Greek Natural Philosophy in the Middle Ages: Islam and Western Christianity. The Review of Metaphysics, 613, 503-526. Retrieved De,from http://www.jstor.org/stable/20130975.

Gözütok, Şakir. (2006). İslam Eğitim tarihinde Müesseleşme, Dilli Araştırmaları.

Gutas, Dimitri,.(1998). Greek Thought, Arabic Culture: The Graeco-Arabic Translation Movement in Baghdad and Early Abbasaid Society London: Routledge.

Garth Fowden.(2004). Alexandria between Antiquity and Islam: Commerce and Concepts in First Millennium Afro-Eurasia, Online ISSN: 1867-0318, Millennium | Volume 16.

Gördük, Yunus Emre. (2011). İşari Tefsirin Mahiyeti, Meşruiyeti ve Batıni Yorumdan Farkı, Marife: Dini Araştırmalar Dergisi [Bilimsel Birikim], 2011, cilt: XI, sayı: 2 ,

Gündüz, Şinasi. (2017). “Alegorik tefsir” Din ve İnanç sözlügüu, İstanbul: Vadi Yayınları.

H. J. Blumenthal. (1972) Alexandria as a Centre of Greek Philosophy in Later Classical Antiquity, Berlin: Egyptian University of Liverpool.

Hussein El-Zohary. (2016). The Late School of Alexandria and Its Influence on Islamic Philosophy, Head of The Academic Studies \& Events Section Manuscript Center Academic Research Sector Bibliotheca Alexandrina.

Harry Austryn Wolfson. (2001)Kelam Felsefeleri Müslüman-Hıristiyan-Yahudi Kelamı. (Turhan, Kasım, Çev.) İstanbul:Kitabevi.

Hobson, John. (2015). M. Batı Medeniyetinin Doğulu kökenleri. (Ermert, Esra, Çev.) İstanbul: Yapı Kredi Yayınları.

Harrington, L. (2003). "Allegory", New Catholic Encyclopedia, Second Edition, Detroit: Thomson \& Gale.

İbrahim, Fazıl Halil. (2001).Emeviler Döneminde Tercüme Faaliyetleri ve İlmi Gelişmelerin Öncü Hareketleri,. (Aslan, Ahmet, Çev.) Şanlurfa: Harran Üniversitesi İlahiyat Fakültesi Vakfı Yayınları.

İnan, Ahmet. (2006). Harran Okulu, 1. Uluslararası Katılımlı Bilim Din ve Felsefe Tarihinde Harran Okulu Sempozyumu. Şanlıurfa: Şelale Matbaasu.

Keskin, İbrahim. (2014). Modernizmin Kıskacından Postmodern Dünyaya Din ve İslam, İstanbul: Sentez Yayıncilık. 
Kalın, İbrahim, (2007). İslam ve Batı. Ankara: İsam Yayınları.

Kayacık, Ahmet. (2004) Bağdat Okulu. İstanbul: Üniversite Kitabevi.

(2009). Bağdat'tan Endülüs'e Mantık Geleneği ve İbn Rüşd. Doğu-Batı İlişkisinin Entelektüel Boyutu İbn Rüşd'ü Yeniden Düşünmek: İbn Rüşd, cilt: II.

Fr.Tadros Y. Malaty. (1994). The School of Alexandria Book One Before Origen,(Jersey City: St. Mark's Coptic Orthodox Church.

Majid Fakhry. (2000) 'Philosophy and Theology: from the Eighth Century CE to the Present,' in J. L. Esposito, ed. The Oxford History of Islam Oxford University Press.

Macleod, Roy (2006). İskenderiye Kütüphanesi Antik Dünyanın Öğrenim Merkezi, Ankara: Dost Yayınları.

Namık, Mustafa. (1993). Küçük Felsefe Tarihi. İstanbul: Tefeyyüz Kütüphanesi.

Keklik Nihat. (1969). İslam Mantık Tarihi, İstanbul: Edebiyat Basımevi.

Önkal, Ahmet. (1998) "Hicret", Türkiye Diyanet Vakfı İslâm Ansiklopedisi Ankara: TDV Yayınları, 17/459.

Özgüdenli, Osman Gazi. (2004) "Merv”, Türkiye Diyanet Vakfı İslâm Ansiklopedisi Ankara: TDV Yayınları.

Paul Getty, (1996). Alexandria and Alexandrianism, California: Library of Congress Cataloging-inPublication Data.

Rudolf Pfeiffer,(1968). History of Classical Scholarship from the Beginnings to the End of the Hellenistic Age, New York Oxford University Press,

Rescher, Nicolas, (1964). The Development of Arabic Logic, Pittsburgh.

Sönmez, Zekiye. (2012). İslam'ın ortaya çıktığı dönemde Arap Yarımadasında Hiristiyanlık. İstanbul: Diyanet Vakfi Yayınları.

Şelebi, Abdülcelil. (2004). Batınî Tefsirinin Doğuşu ve Nedenleri. (Arslan, Gıyasettin, Çev.) Fırat Üniversitesi İlahiyat Fakültesi Dergisi.

Sandra Toenies Keating. (2008). What Catholics Should Know About Islam, General Editor.Father Juan-Diego Brunetta, New Haven: Knights of Columbus Supreme Office.

Tarakçı, Muhammed. (2010). Origen ve Alegorik Kitab-1 Mukaddes Yorumu", Bursa: Uludağ Üniversitesi İlahiyat Fakültesi Dergisi, 1/9.

Tortuk, Bilgehan Bengü Sinan. (2006). B. Sabit'e Göre Hikmet ve Edebin Tazammunları, I. Uluslararası Katılımlı Bilim Din ve Felsefe Tarihinde Harran Okulu Sempozyumu, cilt: I.
Kaya, Mahmut. (2004). "Meşşâiyye” Türkiye Diyanet Vakfı İslâm Ansiklopedisi Ankara: TDV Yayınları, 29/393.

L. E. Ramelli.(2012). Philo as Origen's Declared Model: Allegorical and Historical Exegesis of Scripture, Boston: Christian-Jewish Learning at Boston College.

Utku, Ali. (2010). "Ahmet Midhat: "Darülfünun Kürsüsünden Felsefe Tarihi Dersleri, Kutadgubilig: Felsefe - Bilim Araştırmaları, 18. sayı (İstanbul Üniversitesi Felsefe Bölümü Özel Sayısı).

Ülken, Hilmi Ziya. (1983). İslam Felsefesi Eski Yunandan Çağdaş Düşünceye Doğru. İstanbul: Ülken Yayınları.

Vural, Mehmet. (2016). İslam felsefesi tarihi İslam düşüncesinin tarihsel seyri. Ankara: Elis Yayınları.

Yücel, Ahmet. (2003). Oryantalistler ve Hadis. İstanbul: M.Ü. İlahiyat fakültesi vakfı yayınları.

(2012). Yüksel, Ahmet Turan, İslam'da Bilim Tarihi. Konya: Kitap Dünyası Yayınları.

Willem Hendrik Oliver. (2018). Influence of the Catechetical School of Alexandria on the growth and development of Christianity in Africa, Unısa: Unıversity Of South Africa.

William Montgomery Watt. (2000). Müslüman-Hıristiyan Diyaloğu-Yanlış Anlaşılmaların Eleştirisi. (Aydın, Fuat, Çev.) İstanbul: Birey Yayınları.

https://en.wikipedia.org/wiki/Lighthouse of Alexandria (Erișim: 05.06.2020

https://www.ancient.eu/article/207/what-happened-to-thegreat-library-at-alexandria/ Erişim: 05.06.2020

https://en.wikipedia.org/wiki/Allegorical_interpretations_of _Plato (Erişim: 05.06.2020)

https://tr.wikipedia.org/wiki/GrekBaktriya Krall\%C4\%B1\%C4\%9F\%C4\%B1 (Erișim: 10/10/2020)

https://tr.wikipedia.org/wiki/Merverișim tarihi 05.06.2020(Erişim: 06.06.2020)

https://www.historicjesus.com/glossary/jewsofalexandria.ht ml (Erişim: 07.06.2020)

https://www.dunyadinleri.com/tr-TR/dunyadinleri/Huristiyan-kutsal-metinleri/oku_kitab-imukaddes-tefsirleri(Erişim: 12.06.2020)

http://plato.stanford.edu/entries/arabic-islamic-mysticism/( Erişim: 11.06.2020). 


\section{Extended Abstract}

There is no serious dispute that Islamic sciences were shaped by their own resources during their formation period. We can say that many branches of science, especially Tafsir, Hadith and Fiqh, are fed by the basic sources and internal dynamics of Islam. It is possible to say that in this period, Muslims did not have foreign cultural experience and their products were nourished by the dynamics of Islam. Despite this, it has been claimed that the Islamic thought lost its originality as the Muslim conquest policy expanded and encountered different cultural basins. Rather, in these claims made by orientalists, it is stated that Muslims serve as a mere tool between Greek culture and modern Western thought.

Those who oppose this claim of the orientalists argued that Muslims had an influence on the rise of the West, and although there were encounters with different cultures and minor interactions in Islamic thought, this interaction was not as great as the orientalists claim. According to them, Muslims did not only transmit the knowledge of the Greeks, but also internalized, deepened and enriched within themselves. In fact, according to some, the West today owes its rise to the East, more specifically to the Muslims. Therefore, those who defend this idea argued that Muslims contributed to the rise of modern Western civilization.

It is a claim that requires proof that Muslims are seen as merely a bridge that transmits Greek thought. In the classical period of Islamic thought, the copying of original works other than translations and commentaries and the fact that there are many Islamic philosophers' works that have not been translated into Latin are enough to dismiss the evaluations that Islamic thought is merely a bridge. Muslims corrected many mistakes in ancient culture and reached their own unique conclusions. As a matter of fact, it can be easily said that the sciences of Algebra and Chemistry have become an independent science by the hands of Muslims.

The interaction between culture and civilizations is natural and civilization or culture cannot be attributed to a nation / group. Undoubtedly, there is an interesting similarity between civilization and an infectious disease. Accordingly, both pass from one community to another through contact. There is no independent culture or civilization on its own. Culture and civilizations interact with other civilizations. In this sense, it is natural that different civilizations have contributed to the formation of Islamic thought.

To understand the extent to which Islamic thought was influenced by other cultures in the classical period, one can look at the Alexandria school. The Alexandria School is centrally located in keeping different beliefs together. It is thought that the Alexandria School, which advocated Hellenistic philosophical doctrine when it was first established, is connected with many religions and beliefs, especially Jewish and Christian theology, with its pluralistic and eclectic structure. As an ancient school that started in the 4th century BC and lasted for about a thousand years, the Alexandria School previously influenced Judaism through Philo and Christianity through Clement and Origen. It seems that the pluralistic and eclectic structure of the Alexandria School is actually connected with the city of
Alexandria. Because the city of Alexandria, with its cosmopolitan structure, is the place where almost all races of humanity live. Westerners, who cannot accept that the Alexandria School had an influence on Jewish and Christian culture, but did not affect Islamic culture, continue to claim that it also influenced Islamic culture.

In the cosmopolitan city of Alexandria, it can be said that there is not only one school but more than one school. Allegorism and philosophy dominate all of these schools. Great philosophers like Plato and Aristotle; Being the center of important philosophical movements such as Septism, Stoicism and Yeni-Platonism, Alexandria Schools also pioneered the development of sciences such as mathematics, astronomy, medicine, sociology, logic, geography.

The Alexandria School has historically largely lost its existence before the formation of the Islamic sciences. However, the thought and cultural background represented in the Alexandria School has continued to influence in different ways. While this study aims to reveal the extent to which Islamic sciences may have been influenced by a different cultural environment, based on the example of the Alexandria School, on the other hand, it aims to analyze the means by which the Alexandria School creates this effect.

The Alexandria School is also important in showing the dimensions of the interaction between an ancient philosophical tradition and a heavenly religion. In this sense, the Nestorian-Monophysite Churches and Christian Church Fathers of the Alexandria School, which had the greatest transformation in the third and fourth centuries by influencing both Patristic philosophy and councils, through its relationship with Christianity. allegedly influenced Muslims. In addition, it was stated that the Alexandria School, which pioneered the development of sciences such as Mathematics, Geometry, Algebra, Medicine and Astronomy, left an important legacy to Muslims in these areas. In order to end the dispute between Aryus, one of the prominent members of the Church of Alexandria, and Atanasius of Alexandria, the Bishop of Alexandria, 321 Nicaean councils were convened at the call of the Emperor and the ideas of Ataniasius of Alexandria were accepted. In this sense, with the removal of the pressure on Christians, we see that the theological debates in Christianity are around the members of the Alexandria Church. In this sense, the tradition of Christians making philosophical and logical inferences in their theology has been helpful in defending the beliefs of Muslims.

The Alexandria School had a significant influence on Islamic thought in sciences such as logic, philosophy, and medicine. Especially the works of late period commentaries of Aristotle and Plato in Alexandria had an effect on Muslim philosophers' interpretation of Greek philosophy. Apart from this, the training council had an undeniable effect on the subjects related to the lesson circle and the method of science.

As can be seen in the example of the Alexandria School, Islamic thought has not taken any cultural accumulation as it is, interpreted it according to its own values and world of thought and made it unique. It appears that the Alexandria School did not have as dominant influence on Islamic thought as Judaism and Christianity. 
117 Aytepe, N. / Anemon Muş Alparslan Üniversitesi Sosyal Bilimler Dergisi, 2021 9(IDEKTA) 105-116 